\title{
Behaviour of Co binder phase during diamond deposition on $\mathrm{WC}-\mathrm{Co}$ substrate
}

\author{
B. S. Park \\ Department of Metallurgical Engineering, Yonsei University, Shinchondong, Seodaemoongu, Seoul 120-749 (South Korea) \\ Y.-J. Baik*, K.-R. Lee and K. Y. Eun \\ Ceramic Processing Laboratory, Korea Institute of Science and Technology, PO Box 131, Cheongryang, Seoul 130-650 (South Korea) \\ D. H. Kim \\ Department of Metallurgical Engineering, Yonsei University, Shinchondong, Seodaemoongu, Seoul 120-749 (South Korea)
}

\begin{abstract}
The movement of the Co-rich binder phase and its interaction with growing diamond particles during deposition were investigated by repeated observations of the same site on a WC-Co substrate surface. Both etched and unetched (as-polished) specimens of WC-5Co were used for deposition. The diamond deposition was carried out using the tungsten filament chemical vapour deposition method. Raman spectra have shown that the quality of the diamond deposited on the etched substrate was better than that on the as-polished substrate. The facet size of the diamond film surface on the as-polished substrate was smaller than that on the etched specimen. These effects were caused by the atomic-scale interaction of Co atoms in the binder phase. A special feature of the diamond film on the as-polished specimen was a very rough diamond film surface. This phenomenon was observed to result from the abnormal movement of the Co-rich binder phase to the deposited diamond particle surface and the subsequent non-uniform growth of particles during deposition. The phenomenological characteristics of the Co-rich binder phase movement were also explained.
\end{abstract}

\section{Introduction}

Diamond-coated insert tools have been considered as the first realizable application of chemical-vapourdeposited diamond thin films. The high hardness and thermal conductivity of a diamond-coated layer can meet the requirements of high speed machining and very smooth finished surfaces. As a consequence of much effort on this subject [1-3], a number of commercial cutting tools have been announced recently $[4,5]$. However, there still remains much doubt about their performances as cutting tools [6].

Materials used as a substrate for diamond coating are generally $\mathrm{WC}-\mathrm{Co}$ alloys or $\mathrm{Si}_{3} \mathrm{~N}_{4}$-based ceramics. One problem with using a $\mathrm{WC}-\mathrm{Co}$ substrate is that a Corich binder phase interacts with the deposited diamond during deposition. The Co-rich binder phase can suppress diamond nucleation and a graphite-like carbon film can deposit on the Co-rich binder phase instead of the diamond film $[7,8]$. Another problem is the large thermal expansion coefficient difference between the WC - Co substrate and the diamond layer, which can induce a large thermal stress at the interface. To over-

\footnotetext{
*Author to whom correspondence should be addressed.
}

come these problems, several methods have been applied. The removal of the Co-rich binder phase near the surface of a WC-Co substrate by etching greatly reduced the formation of graphite-like carbon film deposition [1]. Predecarburization of a hot-pressed Co-free WC substrate before diamond deposition, which recrystallizes the WC grains, greatly enhanced the adhesion strength [3]. Finally, the use of an $\mathrm{Si}_{3} \mathrm{~N}_{4}$ substrate excluded the effect of the Co-rich binder phase and was also very helpful in reducing the thermal stress, because the thermal expansion coefficient of $\mathrm{Si}_{3} \mathrm{~N}_{4}$ is close to that of diamond [8]. All these treatments have been applied to reduce the adverse effects of the Co-rich binder phase on diamond nucleation and growth.

As mentioned above, it is believed that the effect of the Co-rich binder phase on diamond deposition is to reduce the nucleation and subsequent growth of diamond. However, there has been no experimental evidence on how the Co phase or Co atoms migrate during deposition and how they affect the deposition of diamond and the film structure. Another effect of the Corich binder phase on diamond deposition, apart from degradation of the diamond, is roughening of the deposited diamond film surface (this kind of roughness is defined as macroroughness in this paper). Figure 1 shows 


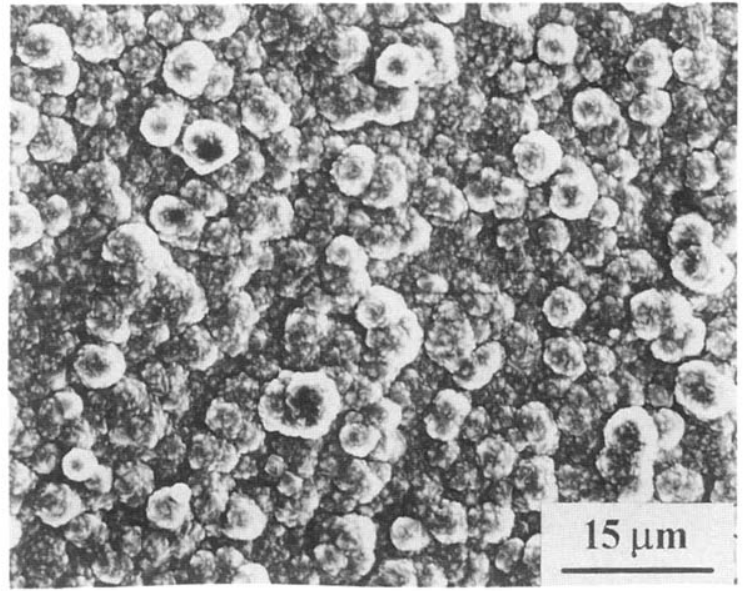

Fig. 1. SEM microstructure of diamond film surface deposited at $950^{\circ} \mathrm{C}$ on as-polished $\mathrm{WC}-\mathrm{Co}$ substrate.

the typical scanning electron microscopy (SEM) morphology of the rough surface of a diamond film deposited under the effect of the Co phase. This rough surface can increase the drag force during cutting and the coated layer could flake even under a low applied stress.

The purpose of this study is to observe how the Corich binder phase interacts with the diamond during deposition. The following interactions are expected. A thin Co layer formed on the WC surface by diffusion at the nucleation stage of diamond particles can help form a graphite-like carbon layer. During growth of the diamond film, degradation of the diamond film quality is also possible owing to a catalytic effect of $\mathrm{Co}$ on the transformation between diamond and graphite. Finally, if the Co layer covers the nucleated particles during growth, the number of particles whose growth continues can be reduced. This results in non-uniform growth of the diamond film and thus a rough film surface. In this study we focused on the third effect of the Co layer and observed the surface of both as-polished (this means that the specimen is only polished, not etched) and etched WC-Co substrates. Nearly in situ observation of the migration of the Co-rich binder phase could be achieved by repeated observations of the same site after deposition for a given time. Auger and Raman spectroscopic analyses were done to determine compositions and structures. The effect of the deposition temperature on the behaviour of the Co-rich binder phase was also investigated.

\section{Experimental methods}

The substrates used in this study were WC-5Co alloy. Their surfaces were polished with $3 \mu \mathrm{m}$ diamond powder. The polished specimens were used for diamond deposition either without etching (as-polished specimen) or with etching of the Co-rich binder phase (etched speci- men). In the case of the etched specimen the Co-rich binder phase was etched with $\mathrm{H}_{2} \mathrm{O}_{2}: \mathrm{H}_{2} \mathrm{SO}_{4}=9: 1$ solution.

The tungsten filament chemical vapour deposition (CVD) method was used for diamond deposition. The filament temperature was $2100^{\circ} \mathrm{C}$, while the substrate temperature was varied from 800 to $1100^{\circ} \mathrm{C}$. The pressure and flow rate were maintained at $40 \mathrm{mbar}$ and $150 \mathrm{sccm}$ (standard $\mathrm{cm}^{3} \mathrm{~min}^{-1}$ ) respectively. An $\mathrm{H}_{2}-\mathrm{CH}_{4}$ gas mixture was used.

The morphology of the specimen surfaces was observed by SEM. We observed the morphology change during deposition by repeated deposition and observation. To identify the same site for observation, we indented the sample surface with a hardness indenter. By this method we could find the site for observation after deposition and carry out nearly in situ observation of the morphology change of the Co-rich binder phase and diamond during deposition. Raman spectra were measured with a SPEX Raman spectrometer using the $514 \mathrm{~nm}$ line of an argon ion laser. Auger electron spectroscopy (Perkin-Elmer 670) was used for composition analysis with an accelerating voltage of $10 \mathrm{kV}$.

\section{Results and discussion}

During liquid phase sintering of the $\mathrm{WC}-$ Co substrate, its surface morphology forms following the equilibrium condition of surface energy minimization [9]. When the substrate surface is polished as shown in Fig. 2(a), the equilibrium at the surface breaks and a new equilibrium condition at the surface tends to form.

During annealing, the surface morphology changes as shown in Figs. 2(b) and 2(c). Two kinds of changes were observed. One is that the Co-rich binder phase, indicated by A in Fig. 2(b), comes out of the site between the WC grains to the surface, but with a very unexpected morphology. Initially it has a very porous form as shown in Fig. 2(b), but as the annealing time increases it seems to densify as shown in Fig. 2(c). Auger spectroscopy analysis (composition A in Table 1) clearly indicates that this phase consists mainly of Co atoms. This composition is nearly the same as that of the binder phase in Fig. 2(a) (composition B in Table 1). The second change is that some WC grains protrude from the substrate surface.

TABLE 1. Composition of the Co-rich binder phase measured by Auger electron spectroscopy

\begin{tabular}{lccl}
\hline Specimen index & W (at.\%) & C (at.\%) & Co (at.\%) \\
\hline A & 7.92 & 24.49 & 67.59 \\
B & 15.51 & 5.87 & 78.62 \\
C & 7.17 & 6.35 & 86.49 \\
\hline
\end{tabular}


(a)

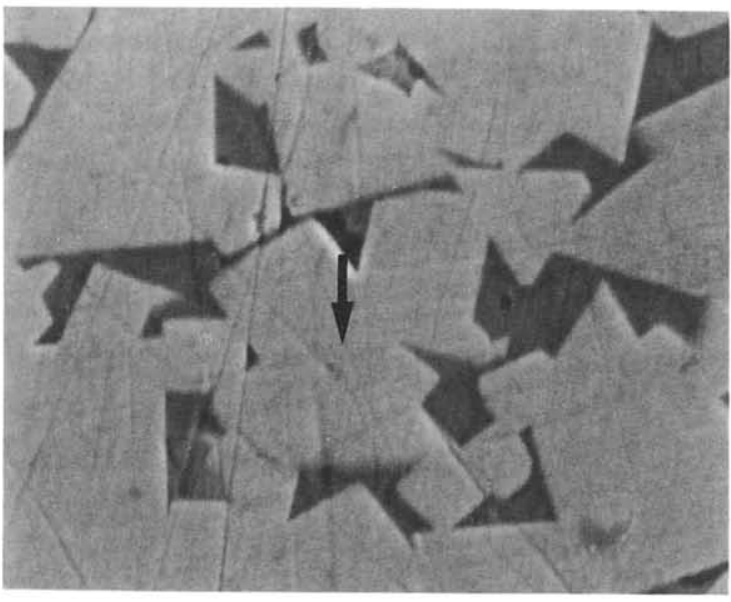

(b)
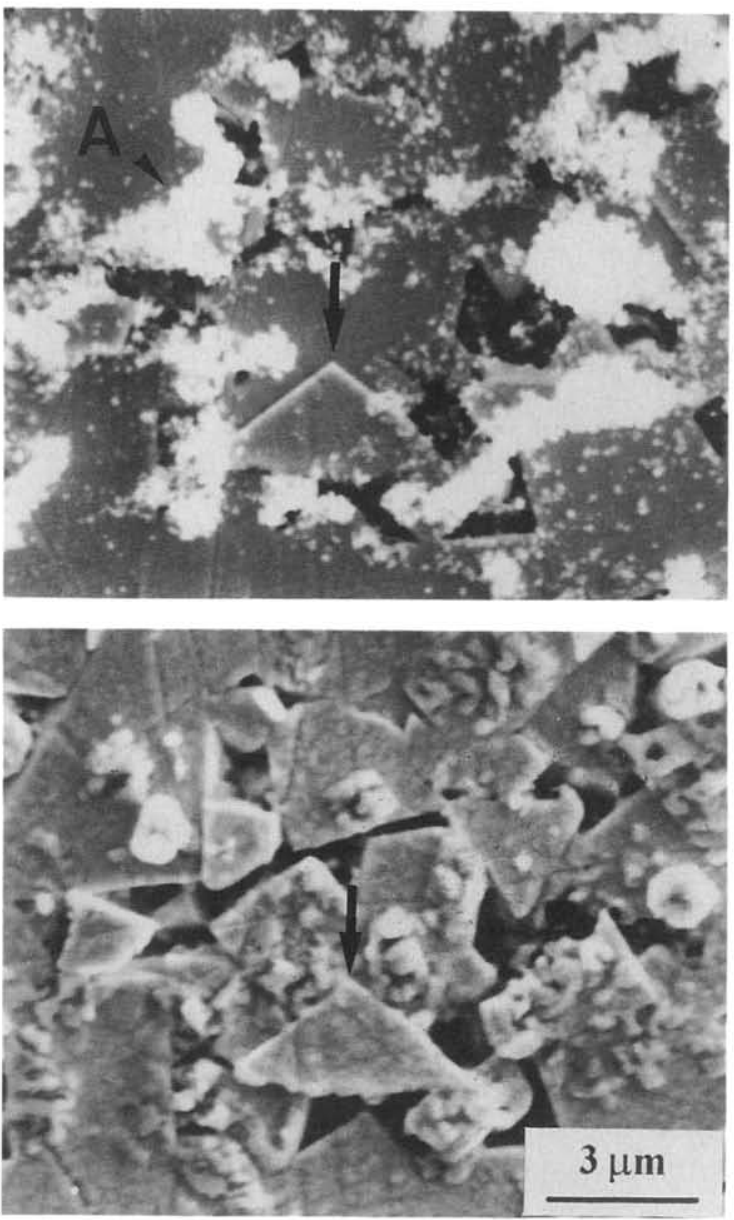

(c)

Fig. 2. SEM microstructures of as-polished WC-Co substrate surfaces annealed at $950^{\circ} \mathrm{C}$ for (a) 0 , (b) 15 and (c) $60 \mathrm{~min}$. An $\mathrm{H}_{2}-0.3 \% \mathrm{CH}_{4}$ gas mixture was used.

The grain indicated by an arrow protrudes gradually as the annealing time increases. The protrusion of WC grains at the substrate surface can significantly weaken the adhesion strength, since it applies stress on the films in the direction normal to the interface.

Together with the migration of the Co-rich binder
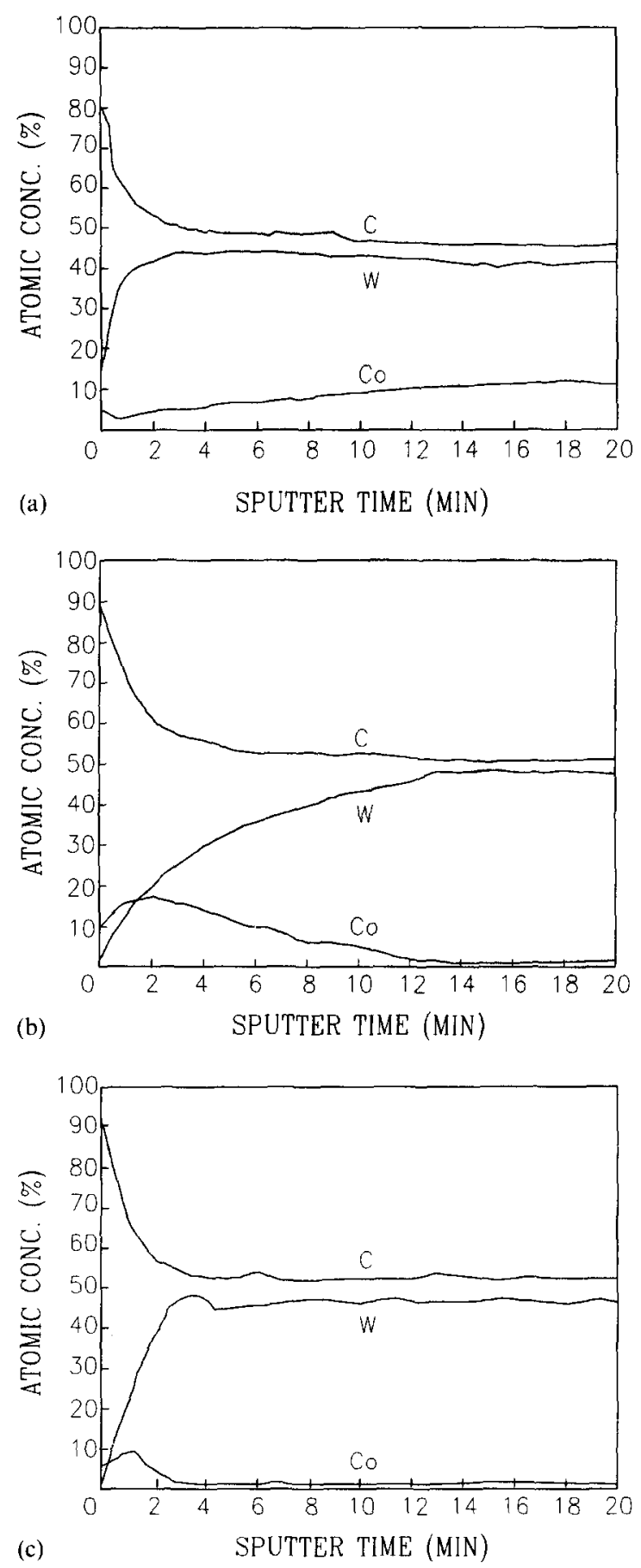

Fig. 3. Depth profiles of composition measured by Auger electron spectroscopy: (a) as-polished specimen; (b) as-polished specimen annealed at $950^{\circ} \mathrm{C}$ for $1 \mathrm{~h}$; (c) etched specimen (etching depth $20 \mu \mathrm{m}$ ) annealed at $950^{\circ} \mathrm{C}$ for $1 \mathrm{~h}$.

phase in the manner shown in Fig. 2, a thin Co layer seems to form on the surface of the WC grains. Figure 3 shows concentration-depth profiles measured by Auger spectroscopy. An electron beam $600 \AA$ in diameter was focused on a small area of the WC grain surface where no visible material like A in Fig. 2(b) was present. Since 
the specimens were sputtered at the same rate, the sputtered depths of the three specimens are believed to be the same. Figure 3(a) shows that the Co concentration beneath the WC grain surface of the as-polished substrate is nearly constant with depth. However, after annealing at $950^{\circ} \mathrm{C}$ for $1 \mathrm{~h}$, the Co concentration at the surface was high and decreased gradually with increasing depth as shown in Fig. 3(b). We can estimate the thickness of the newly formed surface layer during annealing by assuming that the original WC surface is where the concentrations of $\mathrm{W}$ and $\mathrm{C}$ become constant in the depth profile. The value of the Co concentration at the surface is, however, much lower than that of $\mathrm{A}$ in Fig. 2(b).

In contrast the profiles of the specimen with an etching thickness of $20 \mu \mathrm{m}$ show little change in Co concentration after annealing for $1 \mathrm{~h}$, as shown in Fig. 3(c). This is very consistent with the surface morphology change shown in Fig. 4. Figure 4 shows the surface morphologies

(a)

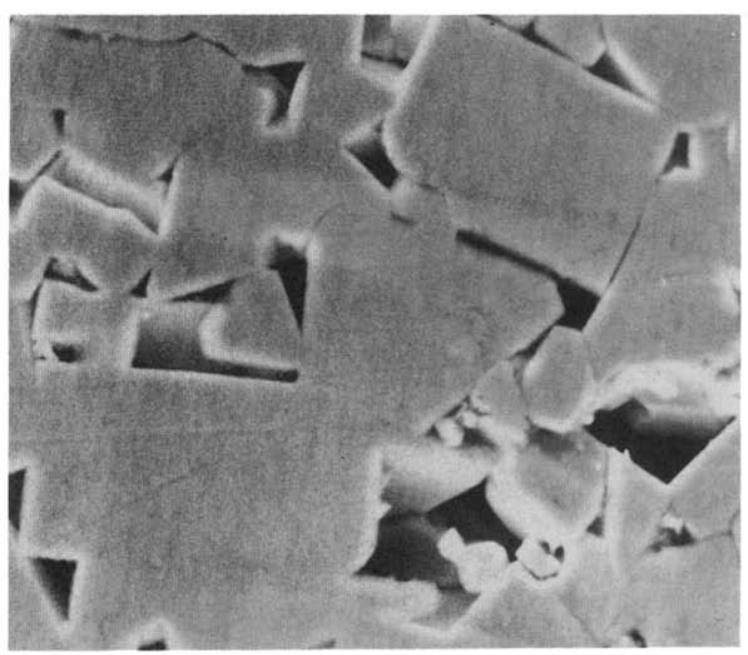

(b)

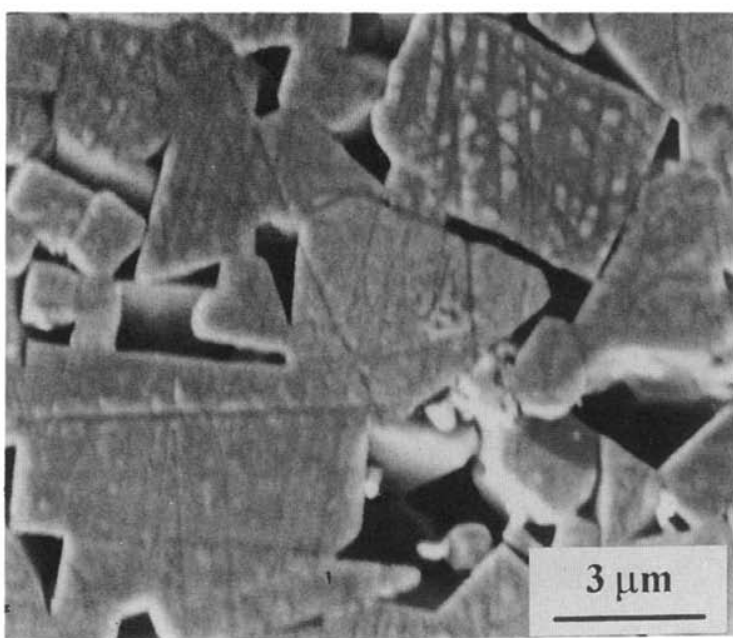

Fig. 4. SEM microstructures of etched WC-Co substrate surfaces annealed at $950^{\circ} \mathrm{C}$ for (a) 0 and (b) $60 \mathrm{~min}$. of specimens (a) just etched and (b) then annealed at $950^{\circ} \mathrm{C}$ for $1 \mathrm{~h}$. No Co binder phase was present on the surface after annealing. This shows that the etching of the Co-rich binder phase of the surface region is very helpful in reducing the Co effect during deposition.

When the annealing temperature was $1100^{\circ} \mathrm{C}$, the surface morphology change shown in Fig. 2 was not observed even in the as-polished specimen. Figure 5 shows the morphology change of as-polished specimens after annealing at $1100^{\circ} \mathrm{C}$. The surface morphologies were very similar to those shown in Fig. 4. No significant change was found with increasing annealing time. However, grooves between WC grains, which were not observed in Fig. 4, formed during annealing. The WC grain surface shows a wave-like morphology which looks like a newly formed surface layer. The thick layer indicated by an arrow seems to be an exaggerated form of such a surface layer. The Co content at the WC grain surface was measured at composition $\mathrm{C}$ in Table 1 . It

(a)

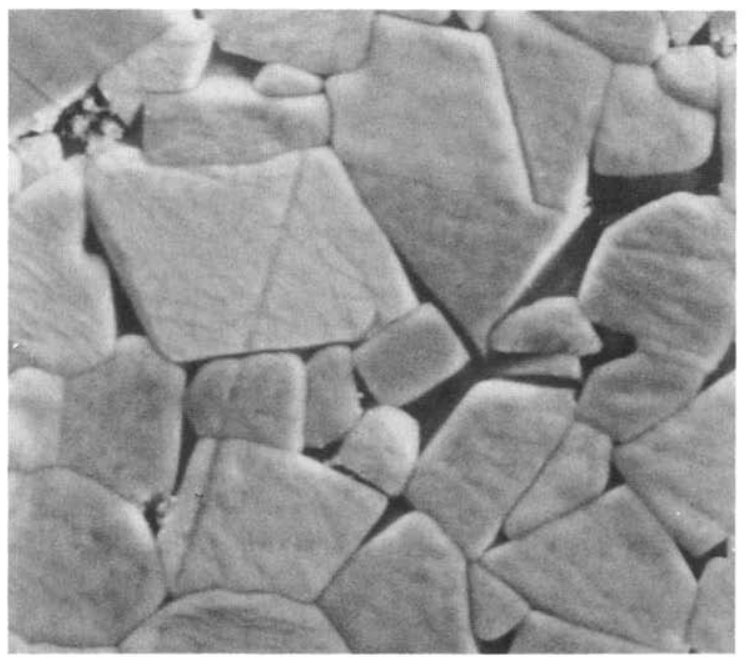

(b)

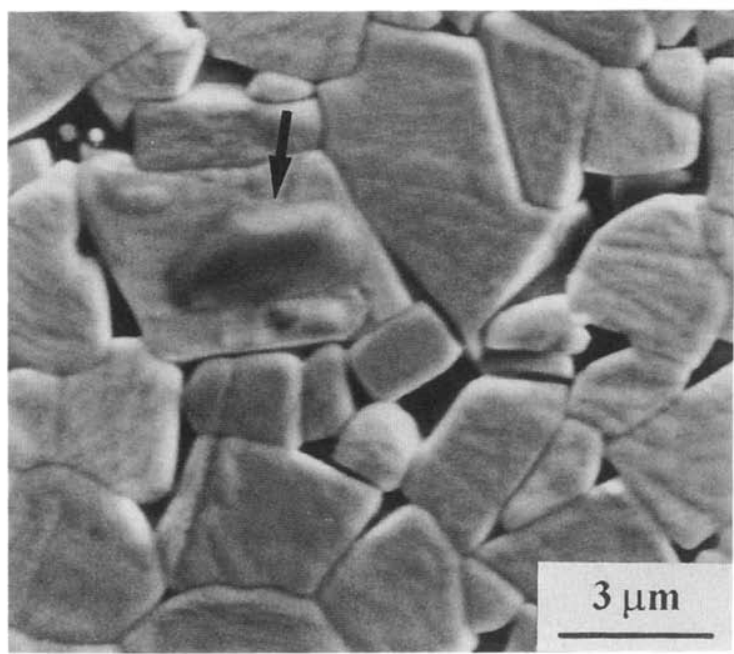

Fig. 5. SEM microstructures of as-polished WC-Co substrate surfaces annealed at $1100^{\circ} \mathrm{C}$ for (a) 15 and (b) $60 \mathrm{~min}$. 
shows a Co concentration similar to or larger than that of the initial binder phase.

For specimens annealed below $1000{ }^{\circ} \mathrm{C}$, the Co-rich binder phase in the as-polished specimen came out with a morphology variation similar to that shown in Fig. 2(b). The rate of movement decreases with decreasing temperature. The Co-rich binder phase has a porous structure like a sponge. However, above $1050^{\circ} \mathrm{C}$ the Co binder phase on the surface shows only a shape as shown in Fig. 5. No porous binder phase could be observed even after annealing for $15 \mathrm{~min}$.

As seen in Fig. 2(c), the porous binder phase densifies to reduce the surface energy as the annealing proceeds. The rate of densification is found to increase very rapidly with increasing temperature. The densification occurs by diffusion. It is thus expected that the activation energy of the material transfer shown in Fig. 2(a) is lower than that of the diffusion process, because the dependence of densification on temperature seems to be more sensitive. Therefore the porous binder phase densifies at the initial stage of movement and consequently the Co binder phase becomes a smooth layer on the WC grain surface. This is the reason why we could hardly see the porous Co-rich binder phase above $1050^{\circ} \mathrm{C}$.

The etched specimen, however, displays a similar surface morphology to that shown in Fig. 4 irrespective of the annealing temperature. This difference in surface morphology change during annealing between the aspolished and etched specimens is related intimately to the surface morphology change of deposited diamond films.

Figures 6 and 7 show the variations in morphology of diamond films deposited on etched and as-polished WC-Co substrates with deposition temperature respectively. The gas mixture composition was $\mathrm{H}_{2}-1.0 \% \mathrm{CH}_{4}$. Two kinds of differences between Figs. 6 and 7 can be found. One is the facet size on the diamond film surface. The average facet size of the diamond film on the aspolished substrate is smaller than that on the etched substrate. The largest difference was seen around a deposition temperature of $900^{\circ} \mathrm{C}$. This is due to secondary nucleation on the growing diamond facet [10], which inhibits the continuing growth of the parent facet. The tendency of secondary nucleation increases with increasing defect density in the diamond [11]. The Raman spectra shown in Fig. 8 also indicate that the quality of the diamond film on the as-polished substrate is lower than that on the etched substrate. Accordingly, the Co atoms are the strong element that increases the secondary nucleation density and degrades the diamond quality during deposition.

Another clear difference is the macroroughness on the diamond film surface. On the film surface of the etched specimen, only the microroughness due to the facet planes exists. However, the as-polished specimens show a roughened surface with a height difference of several micrometres. Figure 9 shows the measured roughness change of the diamond films between the etched and aspolished specimens. The roughness values of the specimens deposited at 800 and $1050^{\circ} \mathrm{C}$ are the same for the as-polished and etched specimens. (The value of the aspolished specimen deposited at $1100^{\circ} \mathrm{C}$ is due to the incomplete coverage of the substrate surface shown in Fig. 6(c).) Between the two the macroroughness shows a maximum around $950^{\circ} \mathrm{C}$. This is consistent with the SEM morphologies shown in Figs. 6 and 7.

Comparison of this result with that of the behaviour of the Co-rich binder phase during deposition, explained in the previous paragraph, indicates that the macroroughness is strongly related to the movement of the Co-rich binder phase. The nearly in situ observation shows how such macroroughness is generated during deposition. Figures 10 and 11 show the microstructural changes observed at the same site after repeated deposition of the etched and as-polished specimens respectively. The diamond particles nucleated on the etched specimen surface are growing without any interruption. The only interruption of growth is the impingement

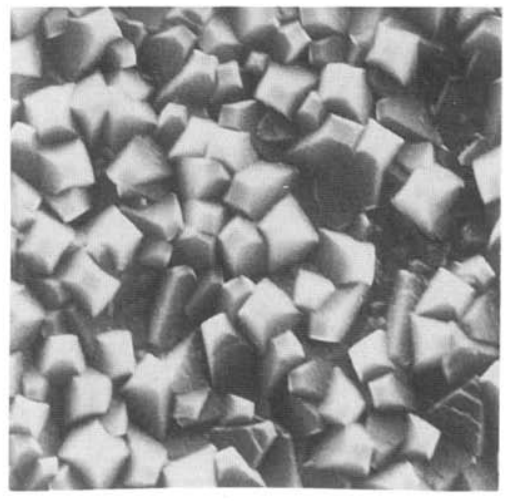

(a)

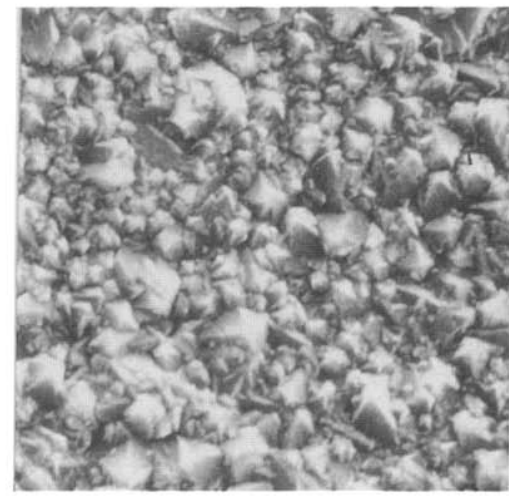

(b)

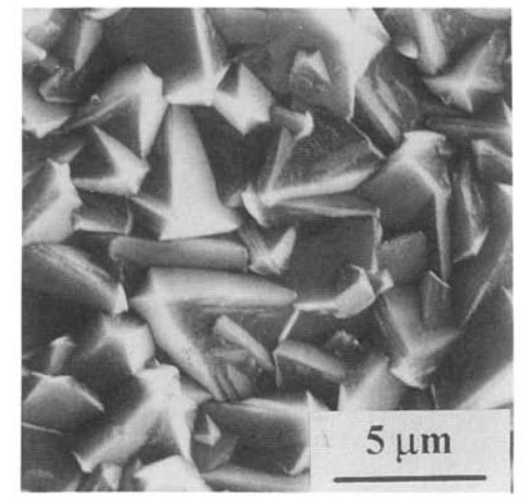

(c)

Fig. 6. SEM microstructures of diamond film surfaces deposited on etched WC-Co substrate at (a) 850 , (b) 950 and (c) $1100^{\circ} \mathrm{C}$. 


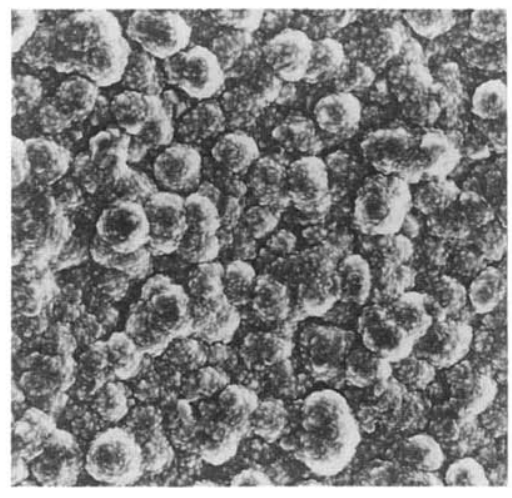

(a)

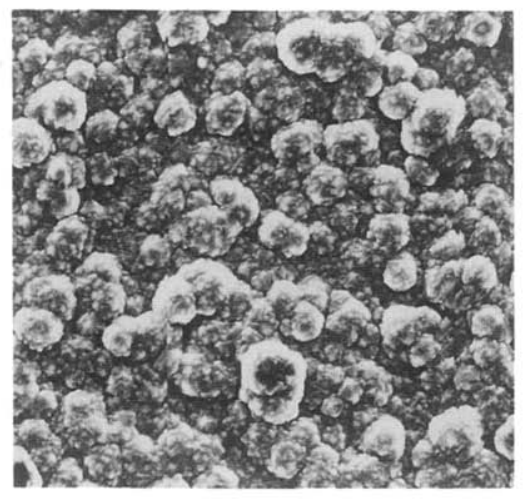

(b)

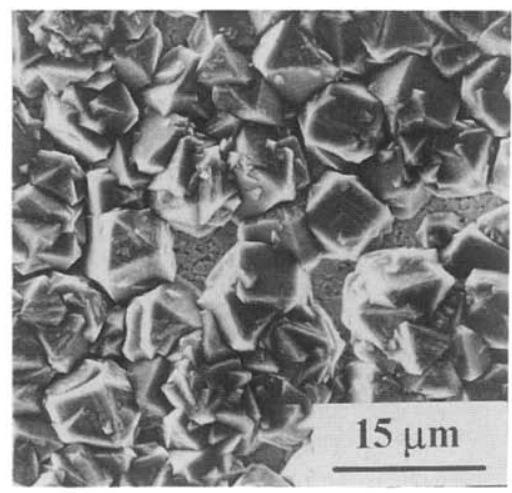

(c)

Fig. 7. SEM microstructures of diamond film surfaces deposited on as-polished WC-Co substrate at (a) 850 , (b) 950 and (c) 1100 C.
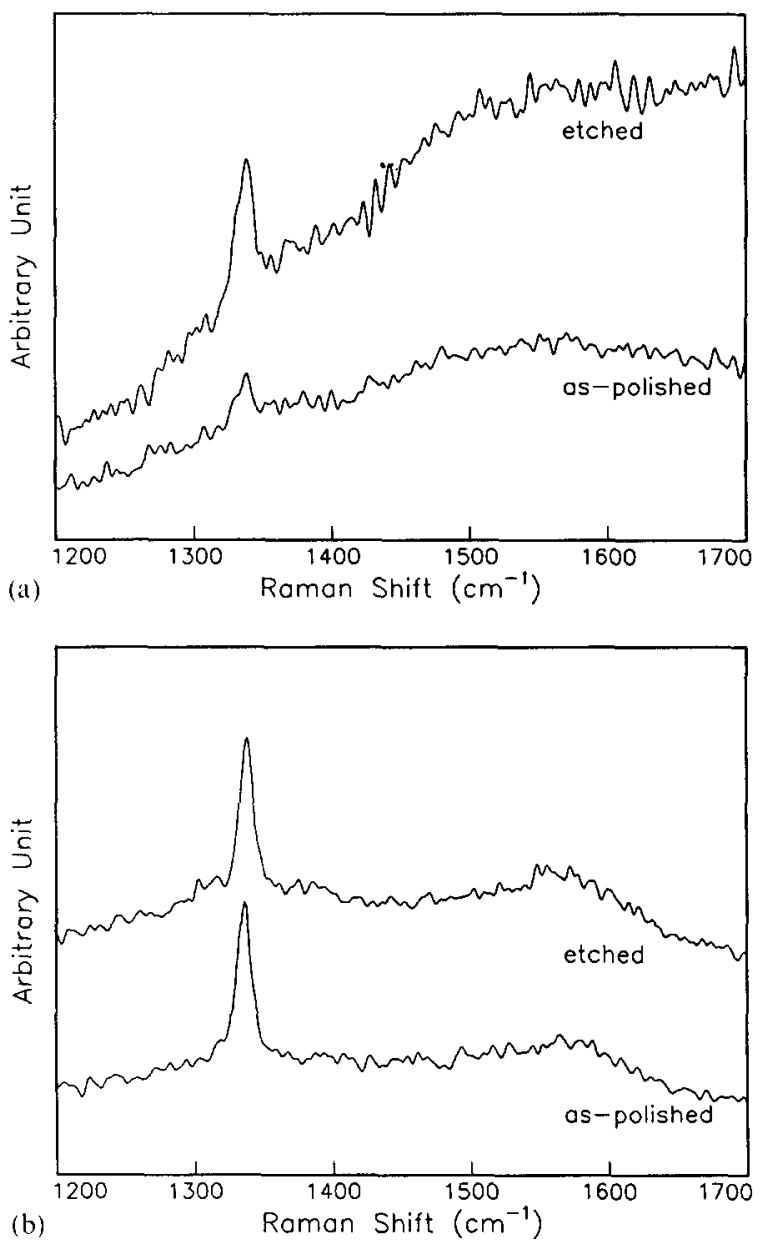

Fig. 8. Raman spectra of diamond films deposited at (a) 900 and (b) $1100 \mathrm{C}$ on etched and as-polished WC-Co substrates.

between particles. However, this could not make nonuniform growth rate parallel to the substrate normal. Once the film forms by the impingement of particles, the film grows uniformly in the direction normal to the surface as shown in Fig. 10(c). Only microroughness caused by the particle facets exists on this film surface.

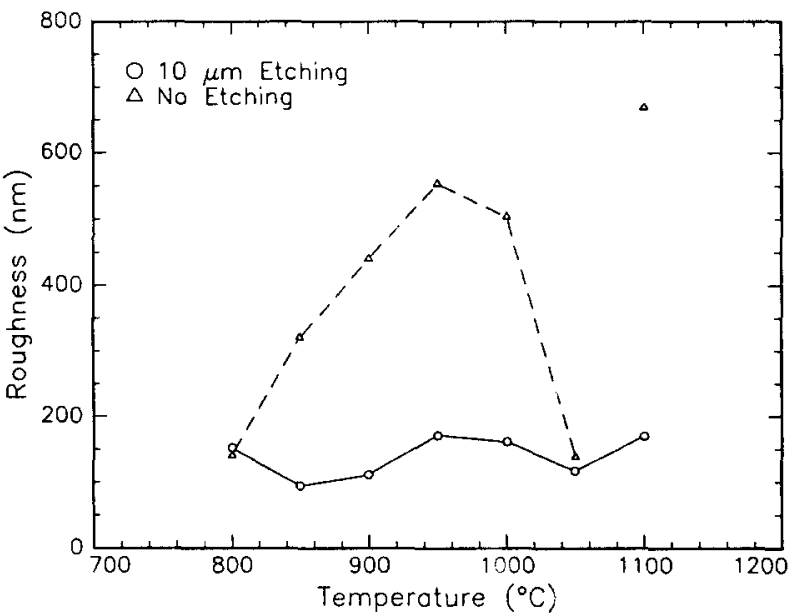

Fig. 9. Variation in surface roughness (measured by a profilometer) of diamond films deposited on as-polished and etched WC-Co substrates.

In the case of the as-polished specimen the diamond particles nucleated preferentially at the WC grain edge as shown in Fig. 11(a). This is very similar to the case of the etched specimens. The growth rate of nucleated particles for the two kinds of specimen is nearly the same by comparison of the particle sizes of Figs. 10(a) and 11(b). Therefore the nucleation and growth of diamond particles for the two kinds of specimen seem to show no difference. However, as shown in Fig. 2, the Co-rich binder phase comes out very rapidly. In Fig. 11 we can also see such a Co-rich binder phase mixed with the growing particles. The series of microstructures of Fig. 11 show that the movement of the Co-rich binder phase covers some of the growing particles (one example is indicated by arrows). Once the particles are covered with the Co-rich binder phase, their growth cannot continue. Only particles that are exposed to the atmosphere can grow further. On the other hand, the Co-rich binder phase was shown to move during deposition. This can be seen in both Figs. 2 and 11. This continuous movement enables the binder phase to cover new 


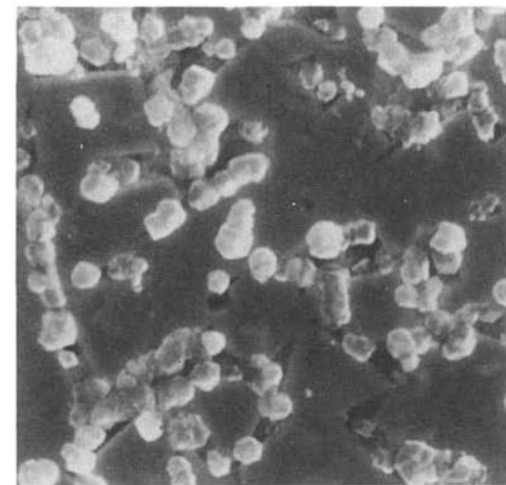

(a)

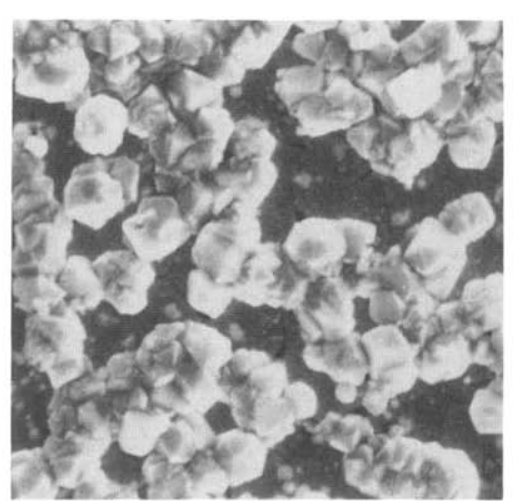

(b)

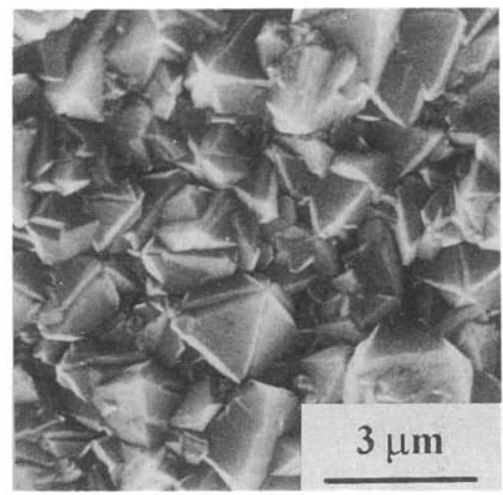

(c)

Fig. 10. SEM microstructures of diamond films deposited on etched WC-Co substrate at $950^{\circ} \mathrm{C}$ for (a) 1 , (b) 2 and (c) $6 \mathrm{~h}$.

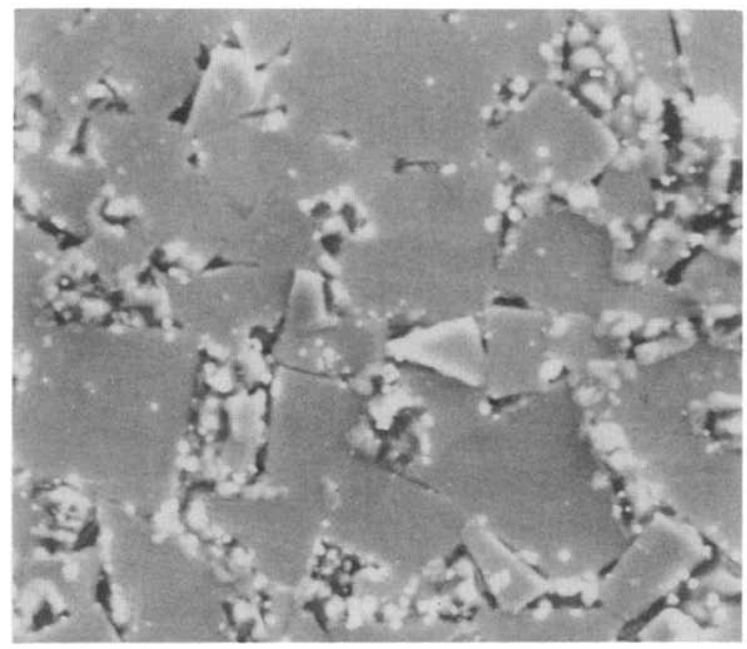

(a)

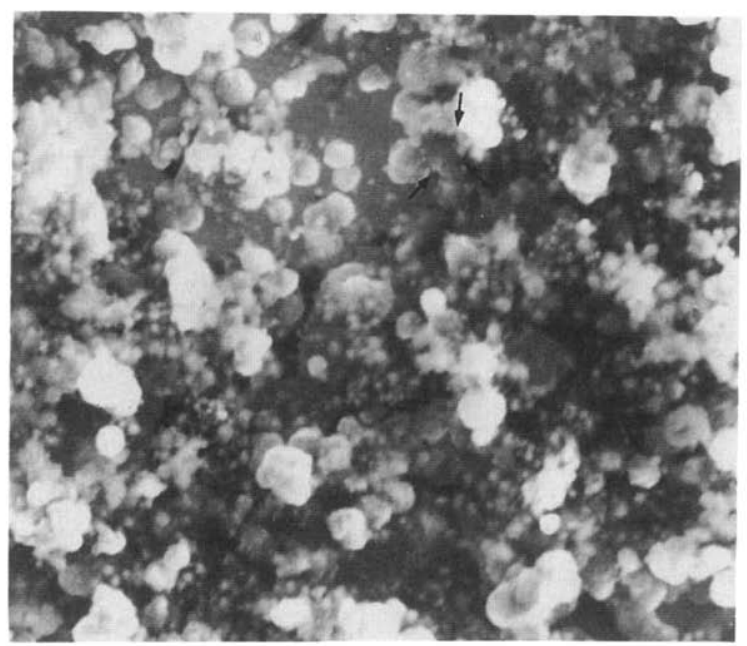

(c)

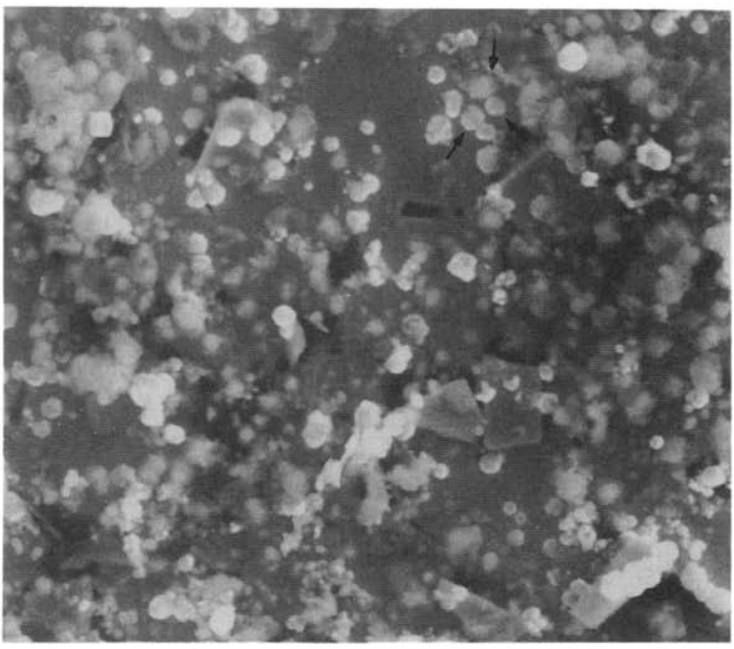

(b)

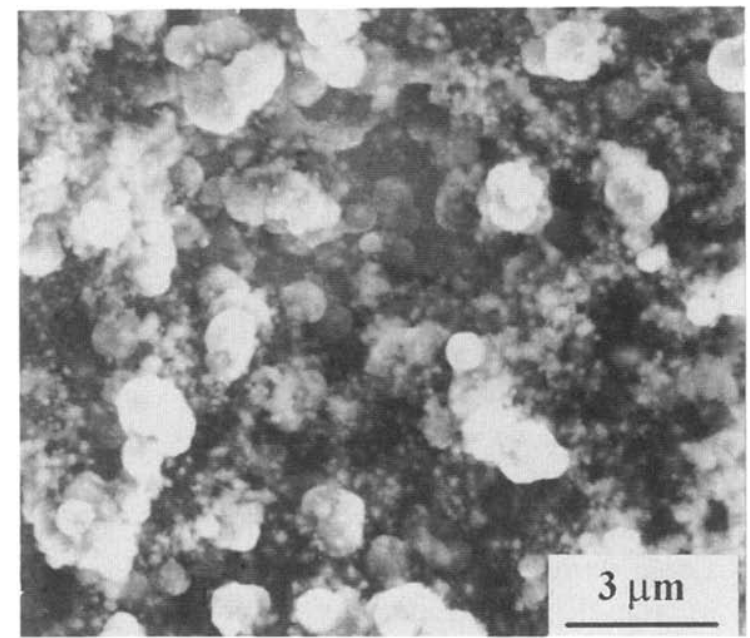

(d)

Fig. 11. SEM microstructures of diamond films deposited on as-polished WC-Co substrate at $950^{\circ} \mathrm{C}$ for (a) $15 \mathrm{~min}$, (b) 1 , (c) 2 and (d) $3 \mathrm{~h}$. 
particles exposed to the gas phase. The probability that the particles are covered increases as the distance from the substrate surface decreases. The density of growing particles is greatly reduced by this coverage effect. This reduced particle density causes surface irregularity, which leads to high roughness and also voids in the film. The binder phase observed with the diamond particles could be seen until $8 \mathrm{~h}$ of deposition had passed. (After $4 \mathrm{~h}$ of deposition the substrate surface was fully covered with cross-linked diamond particles and the Co-rich binder phase.) After the disappearance of the Co-rich binder phase on the film surface, the particles composing the film grew uniformly and no further interruption was observed.

\section{Conclusions}

The effect of the Co-rich binder phase existing in the WC-Co substrate was observed from the viewpoint of the evolution of the surface morphology of diamond films during deposition. The difference between aspolished, non-etched and etched specimens was significant in the final surface morphology of the diamond film. In the case of the etched specimen the film surface showed the morphology that could be obtained on an $\mathrm{Si}$ substrate, i.e. there is very little effect of Co atoms on the diamond deposition. However, in the case of the aspolished specimen the Co-rich binder phase was observed to move out to the film surface by diffusion or material flow just after the deposition started. The interaction between the moving Co-rich binder phase and the growing diamond particles was just the inhibition of growth of particles by particle surface coverage of the Co-rich phase. This coverage of the particle surface appeared to reduce the number of particles that could grow further. Thus the growth of the reduced number of particles that were not covered by the Co-rich phase led to a non-uniform growth morphology which continued until the Co-rich binder phase disappeared.

The mechanism of the Co-rich binder phase movement was not clarified in this study. Two different types of movement were shown. At low deposition temperatures (below $1000^{\circ} \mathrm{C}$ ) the Co-rich binder phase came out in a fashion like a material flow to the surface with a porous shape, while at high temperatures (above $1050^{\circ} \mathrm{C}$ ) a thin Co-rich layer was believed to form on the WC grain surface. To prevent the effect of Co atoms on diamond deposition, it will be very important to clarify the mechanism of the Co-rich binder phase movement.

\section{Acknowledgment}

This work was supported in part by the Ministry of Trade and Industry of Korea.

\section{References}

I H. Suzuki, H. Matsubara and N. Horie. J. Jpn. Soc. Powder Metall., 33 (1986) 262.

2 K. Ito, Diamond coated cutting insert by using carbon monoxide as source gas, Emerging Technology, Applications, and Markets for Diamond and DLC Coatings, Gorham Advanced Materials Institute, Marco Island, FL, October 1989.

3 K. Saijo. M. Yagi, K. Shibiki and S. Takatsu, Surf. Coat. Technol., $43-44$ (1990) 30.

4 N. Kikuchi, H. Eto, T. Okamura and H. Yoshimura, in Y. Tzeng, M. Yoshikawa, M. Murakawa and A. Feldman (eds.), Proc. First Int. Conf. on the Application of Diamond Films and Related Materials, Elsevier, New York, 1991, p. 61.

5 Catalog, Idemitsu DiAPLUS, Chioda, Tokyo, 1990.

6 D. G. Bhat, Diamond Depos. Sci. Technol., 2 (1991) 12.

7 M. Murakawa, S. Takeuchi, H. Miyazawa and Y. Hirose, Surf. Coat. Technol., 36 (1988) 303.

8 S. Soderberg, Vacuum, 41 (1990) 1317.

9 R. M. German, Liquid Phase Sintering, Plenum. New York, 1985.

10 K. Kobashi, Phys. Rev. B, 38 (1988) 4067.

11 Y.-J. Baik, unpublished work, 1990. 